Natural Hazards and Earth System Sciences (2002) 2: 147-155

(C) European Geosciences Union 2002

(1) Natural Hazards

\title{
High resolution snow distribution data from complex Arctic terrain: a tool for model validation
}

\author{
Ch. Jaedicke ${ }^{1}$ and A. D. Sandvik ${ }^{2}$ \\ ${ }^{1}$ University Courses at Svalbard, Box 156, N-9170 Longyearbyen, Norway \\ ${ }^{2}$ Geophysical Institute, University of Bergen, Allegaten 70, N-5007 Bergen, Norway
}

Received: 20 September 2001 - Revised: 18 January 2002 - Accepted: 18 March 2002

\begin{abstract}
Blowing snow and snow drifts are common features in the Arctic. Due to sparse vegetation, low temperatures and high wind speeds, the snow is constantly moving. This causes severe problems for transportation and infrastructure in the affected areas. To minimise the effect of drifting snow already in the designing phase of new structures, adequate models have to be developed and tested. In this study, snow distribution in Arctic topography is surveyed in two study areas during the spring of 1999 and 2000. Snow depth is measured by ground penetrating radar and manual methods. The study areas encompass four by four kilometres and are partly glaciated. The results of the surveys show a clear pattern of erosion, accumulation areas and the evolution of the snow cover over time. This high resolution data set is valuable for the validation of numerical models. A simple numerical snow drift model was used to simulate the measured snow distribution in one of the areas for the winter of 1998/1999. The model is a two-level drift model coupled to the wind field, generated by a mesoscale meteorological model. The simulations are based on five wind fields from the dominating wind directions. The model produces a satisfying snow distribution but fails to reproduce the details of the observed snow cover. The results clearly demonstrate the importance of quality field data to detect and analyse errors in numerical simulations.
\end{abstract}

\section{Introduction}

In cold regions, such as the Arctic or alpine terrain, wind transport of snow plays an important role for the winter snow distribution. The snow is moved from exposed erosion areas to accumulation areas, forming a snow distribution pattern which is typical for the terrain and the prevailing wind conditions. The resulting snow pattern often interferes with the infrastructure in these areas, causing problems for mobility and security. The accumulating snow masses block traffic lanes,

Correspondence to: Ch. Jaedicke (chrisj@unis.no) bury houses and infrastructure, and significantly increase the risk of avalanches. Additionally, the decreased visibility on traffic lanes during snowstorms can cause severe difficulties for any vehicle.

These problems caused an early interest in the process of snow drift. Already Johnson (1852) observed and documented areas in complex terrain, which can be exposed to snow accumulations, and tested a number of snow fences. Mellor (1965) gives an overview of the effects of snow drift on infrastructure. He shows that the consideration of snow drift in the design and the correct location of buildings and infrastructure can prevent severe problems. Snow fences are used to protect the effected areas from snowdrifts. They collect the blowing snow by breaking the natural wind flow. This causes turbulence in which the snow can settle down. Different snow fences were tested and applied by Tabler (1980, 1988, 1994), Zhonlong and Yuan (1980). Also, the design of roads and road structures can be improved to avoid snowdrift problems (Norem, 1974; Tabler, 1994).

The detailed study of drifting snow showed that saltation and suspension are the major transport modes (Budd et al., 1966; Pomeroy and Gray, 1990). The wind has to reach a certain threshold velocity before the snow particles loosen from the surface (Schmidt, 1980). They start to jump up in hyperbolas from the ground and saltate along the snow surface. As the wind speeds increases, lighter particles are picked up by the turbulent eddies of the boundary layer and are transported in suspension. Airborne snow particles surrounded by unsaturated air will start to sublimate. This is a major loss of snow mass from seasonal snow covers to the atmosphere (Schmidt, 1972, Pomeroy et al., 1997; Bintanya, 1998; Dery et al., 1998; Mann et al., 2000). For the future design or for the improvement of structures in snowdrift areas, knowledge of the erosion and accumulation pattern in the terrain allows one to avoid the most affected areas. This kind of information can be provided by field surveys (Norem, 1974) or three-dimensional numerical snowdrift models. Such models are either based on a wind field generated by a separate wind model (Pomeroy et al., 1997; Liston and Sturm, 1998; 


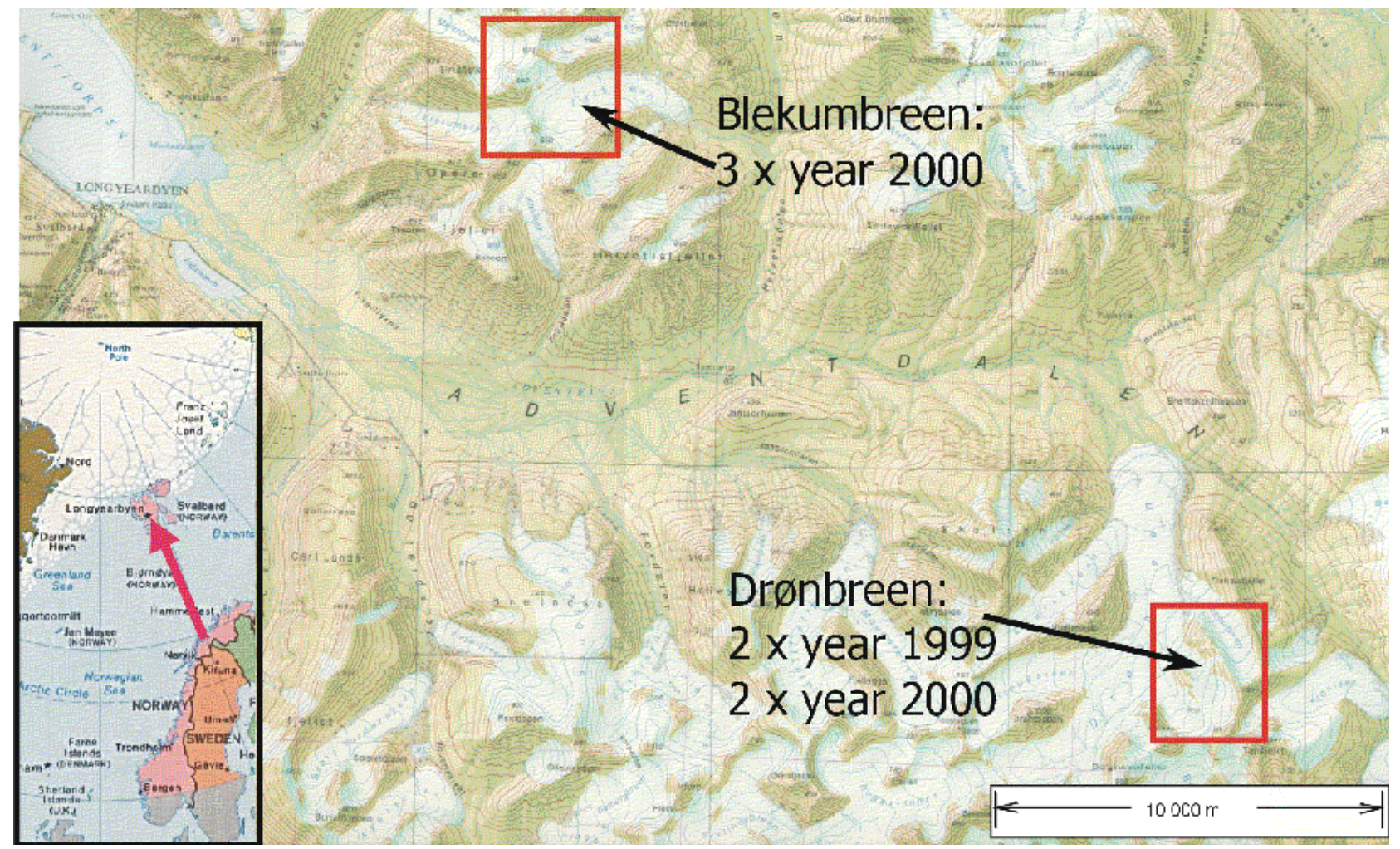

Fig. 1. Map of the valley Adventdalen showing the two study areas and the number of surveys during the field season 1999 and 2000 . The position of Spitsbergen in relation to the main land Norway is shown in the small map in the left corner.

Michaux et al., 2000) or use two-phase flow models to simulate the snow transport (Gauer, 1998; Sundsb $\varnothing$ and Bang, 1998; Thiis, 1999). For the development and verification of such models, high quality field data for the entire model domain is needed.

This study presents high resolution snow distribution data in a complex terrain. The data covers two study areas which were surveyed for two and three times during the spring of 1999 and 2000, respectively. A ground penetrating radar system is developed for the application under Arctic conditions and is used for the surveys. The snow distribution in one of the study areas is simulated by a three-dimensional numerical snowdrift model. The model calculates the snowdrift for the saltation and the suspension layer, based on wind fields generated by a mesoscale meteorological model.

\section{Site description}

The two study areas are located at $78^{\circ} \mathrm{N}$ on the island of Spitsbergen about $40 \mathrm{~km}$ from the settlement Longyearbyen (Fig. 1). They are $4 \times 4 \mathrm{~km}$ (Blekumbreen) and $3 \times 4 \mathrm{~km}$ (Drønbreen) in size and reach from elevations of $300 \mathrm{~m}$ to $1000 \mathrm{~m}$. The areas are partly covered by glaciers. The icefree ground consists of moraine materials and sedimentary rock without higher vegetation. This is a good cross section of many typical features of the terrain of western Spitsbergen. The annual mean air temperature is $-6^{\circ} \mathrm{C}$ and is $-16^{\circ} \mathrm{C}$ in the coldest period, February to March. The prevailing wind direction in the area is from the east during the winter months. The amount of annual precipitation in the area is estimated from Hagen et al. (1993) to be $600 \mathrm{~mm} / \mathrm{a}$. Figure 2 shows the meteorological conditions during the winter season 1998/1999 taken from ECMWF (European Centre for Medium range Weather Forecast) re-analysis (six hour values at the $1000 \mathrm{hPa}$ level). The precipitation data stems from the meteorological station at Longyearbyen airport. The absence of higher vegetation and melting periods during winter give ideal conditions for snowdrift experiments.

\section{Field studies}

The snow distribution in the two study areas was surveyed during spring 1999 (Drønbreen) and spring 2000 (Blekumbreen). The snow depth was measured by a ground penetrating radar (GPR) system. The GPR is based on a commercially available system (Sensors and software, 1995) which was further developed for the use in Arctic conditions. The whole system is moved in a specially designed sledge behind a snowmobile (Fig. 3). This sledge contains the radar antennas, the control unit, a field PC, GPS and a power supply. The electric power supply is based on a $12 \mathrm{~V}$ car battery and is designed to work in cold conditions down to $-30^{\circ} \mathrm{C}$. The radar was triggered off every metre by an odometer wheel and data are continuously recorded on the field PC. 



Fig. 2. Meteorological conditions during the winter season 1998/1999 (ECMWF re-analysis, six hour values at the $1000 \mathrm{hPa}$ level). The precipitation data is derived from the meteorological station at Longyearbyen airport.

The GPR can be equipped with 225,450 and $900 \mathrm{MHz}$ antennas. The frequency of the system decides the penetration depth and resolution of the instrument. High frequencies generate smaller wavelengths and allow for a higher resolution while the penetration depth decreases. The $900 \mathrm{MHz}$ antennas allow for a penetration of up to $10 \mathrm{~m}$ in snow, which is sufficient for the conditions in the study areas. The radar system measures the travel time from emitting the radar signal into the ground until the receiver antenna detects the reflected signal. The velocity of the electromagnetic waves in the snow has to be known to calculate the snow depth. Both snow density and the free water content of the snow influences the velocity (Annan et al., 1995). A high content of free water will slow down the electromagnetic wave in wet snow. The velocity of the radar wave in snow can be found from manual measurements of the snow depth just between the antennas of the radar.

During the surveys the instrument was calibrated in the field by probing the snow several times with an avalanche probe. This calibration yields an accuracy of $+/-0.05 \mathrm{~m}$ snow depth at $900 \mathrm{MHz}$. The achieved radar profiles are digitised and the snow depth is calculated using the calibration values from the survey. The water equivalent is calculated from the radar snow depth and snow densities, measured in several snow pits. A similar radar system was applied by Sand and Bruland (1998), who measured snow depth in several catchments on Spitsbergen.

Some of the radar profiles were continued manually in steep terrain, which was not accessible for the snowmobile. The snow free areas of bare ground were carefully observed and marked on a map. The radar profiles were marked with bamboo pins to allow for an accurate repetition of the measurements along the same lines. All profiles were positioned by differential GPS. The radar, together with the manual measurements and bare ground observations, provide approximately 17000 data points for each survey.

\section{Numerical modelling}

\subsection{Model structure}

A simple three-dimensional snowdrift model is used to predict the snow distribution in the study area. The model 


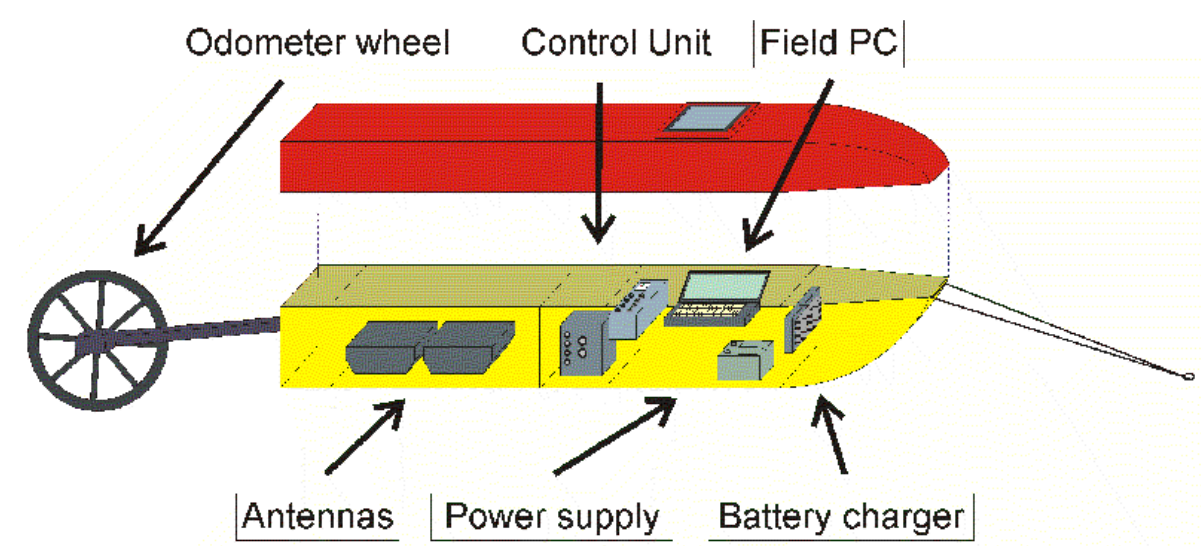

Fig. 3. Schematic plot of the radar sledge. The compartments contain from the left: Spare parts and cables, antennas, control unit, power supply and computer, battery charger. The sledge is about $180 \times 40 \times 50 \mathrm{~cm}$ in size.

is based on wind fields generated by a meteorological mesoscale model. The wind fields are used to calculate the equilibrium snow drift flux at each grid point for a number of typical wind directions. Every six hours, the wind speed given by the ECMWF re-analysis is tested if it exceeds a certain threshold value. If the wind speed is above this threshold, the wind field from the corresponding wind direction is activated. This creates a new snow cover, which is the starting point for the next six hour period.

\subsection{Snowdrift model}

The snowdrift model is mainly based on the work by Pomeroy et al. (1997) and Liston and Sturm (1998). The input wind speed at $10 \mathrm{~m}$ above the ground is generated by the wind model. The model calculates the flux of saltation $Q_{\text {salt }}$ and of suspension $Q_{\text {susp }}$ for each grid point of the simulated wind field using constant values of threshold friction velocity $u_{* t h}(0.25 \mathrm{~m} / \mathrm{s})$ and terminal fall velocity $s(0.3 \mathrm{~m} / \mathrm{s})$. The values of snow concentration $c(z)$ and wind speed $u(z)$ are used, together with constant values of air temperature $\left(-15^{\circ} \mathrm{C}\right)$ and relative humidity $(80 \%)$, in a separate routine to calculate the sublimation from the airborne snow particles (Liston and Sturm, 1998).

\subsection{Wind model}

The non-hydrostatic numerical mesoscale model MEMO (Flassak, 1990; Moussiopoulos, 1994; Grønås and Sandvik, 1999) was used to generate the wind fields for the study area. The model solves the momentum equation, the continuity equation and optionally several transport equations for scalars on a staggered grid. The applied model version includes the following dependent variables of the three wind components: pressure, potential temperature and turbulent kinetic energy. The vertical coordinate is normalised to the underlying terrain. In the present study, the study area (Drønbreen), with a $50 \mathrm{~m}$ resolution, was enclosed in three nesting levels up to $500 \mathrm{~m}$. Vertically, the atmosphere was divided exponentially into 25 terrain following layers from
$10 \mathrm{~m}$ to $4000 \mathrm{~m}$. Only one surface type, snow covered land $\left(z_{0}=0.1 \mathrm{~m}\right)$ was used.

The wind field in the study area will be highly influenced by the atmospheric stability, wind speed and direction. Winter climatology at Spitsbergen is dominated by low-level inversions due to net radiative loss of energy from the surface. The initial model atmosphere is stable stratified (constant potential temperature gradient equal to $0.71^{\circ} \mathrm{C} / 100 \mathrm{~m}$ and $-15^{\circ} \mathrm{C}$ at the surface). Five wind directions (N, NE, E, $\mathrm{SE}, \mathrm{S}$ ) were simulated, imposing a uniform wind of $10 \mathrm{~m} / \mathrm{s}$ at the upstream boundary.

\subsection{Coupling}

The equilibrium snowdrift flux is calculated for each grid point in the model domain separately for the five wind directions. The resulting five erosion fields are applied on the model domain, depending on the wind direction and speed for every six hours during the winter season $(1$ November 1998 - 1 May 1999). For example, $8 \mathrm{~m} / \mathrm{s}$ wind from $48^{\circ}$ in the ECMWF re-analysis activates the NE erosion field and produces a new snow distribution. Due to the limited access of only five wind fields, all wind speeds over the threshold will activate the same wind field based on the $10 \mathrm{~m} / \mathrm{s}$ simulations. The threshold wind speed $(7 \mathrm{~m} / \mathrm{s})$ is a tuning parameter to fit the model results to the observed snow distribution and is constant for the whole winter season.

The precipitation record from Longyearbyen airfield (annual precipitation $200 \mathrm{~mm} / \mathrm{a}$ ) is used to generate the precipitation in the study area. Based on the estimations of Hagen et al. (1993), the precipitation at Longyearbyen airfield is multiplied by a factor of three and a height factor adjusts the precipitation in the study area. The initial snow depth is zero at all grid points and the distribution of snow starts after the first precipitation event. 

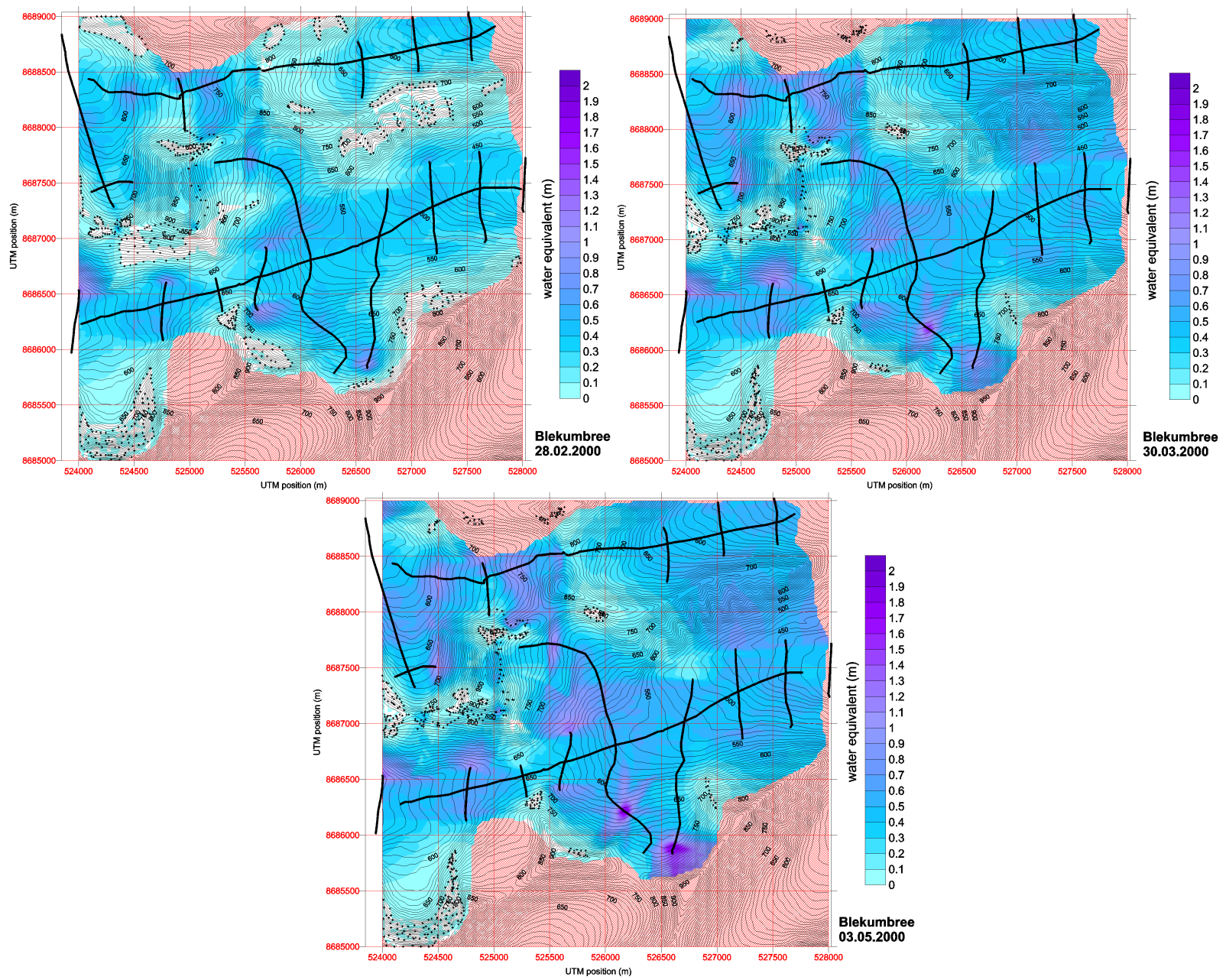

Fig. 4. Snow distribution in the Blekumbreen study area in spring 2000. The three plots show results from the surveys 28 February 2000 , 30 March 2000 and 3 May 2000. Strong black lines are the radar profiles, black crosses indicate areas with bare ground. The pink areas are blank from the interpolation.

\section{Results}

\subsection{Field data}

The results from three surveys of the snow distribution in the Blekumbreen area are illustrated in Figs. 4a-c. The strong black lines show the radar profiles and crosses mark the areas of bare ground. Together, they give a good impression of the data coverage. The data was interpolated to a $50 \mathrm{~m}$ grid using Kriging. Areas without data coverage are blanked to avoid misinterpretation. A detailed accumulation and erosion pattern can be seen in the plots. Mountain ridges and exposed backs are free of snow, while lee slopes and depressions collect most of the snow. The time in between the surveys is roughly one month and the increase of the snow depth can be seen from survey to survey. Accumulation areas increase their snow depth significantly more than the average. The average snow depth is increasing from 170 to 330 and $410 \mathrm{~mm}$ water equivalent (WEQ) for the three surveys. The maximum snow depth at the end of the season is $1600 \mathrm{~mm}$
WEQ. Figure 5 shows the snow distribution in the study area on Drønbreen $(4 \times 3 \mathrm{~km})$ at the end of the season 1999. It was surveyed by the same methods as described above. The situation on Drønbreen is simulated with the help of a numerical snowdrift model.

\subsection{Numerical modelling}

The wind field generated by the MEMO model for $10 \mathrm{~m} / \mathrm{s}$ wind from the prevailing direction east is shown in Fig. 6 . Wind speeds reach a maximum of $15 \mathrm{~m} / \mathrm{s}$ on the mountain ridges and low wind speeds dominate in the valleys. The high resolution of $50 \mathrm{~m}$ includes many details around the topographic features in the study area. The wind directions vary significantly from place to place. Given an adequate snowdrift model, this is a good basis for detailed modelling of snow distribution in the area. The other directions $(\mathrm{N}$, $\mathrm{NE}, \mathrm{SE}, \mathrm{S}$ ) show similar features and including recirculation zones behind step ridges.

The modelled snow distribution at the end of the season is 




Fig. 5. Measured snow depth in the Drønbreen area at the end of the winter season (19 April 1999). The black lines are the radar profiles, black dots show areas with bare ground. The crossed areas are blank from the interpolation.

shown in Fig. 7. It gives a good overview of erosion and accumulation areas. The erosion areas are located in the windward slopes and are partly free of snow. The major part of the accumulation takes place in the lee slopes behind ridges and tops. On the smoother terrain, the simulated snow distribution is rather uniform. The mean snow depths are 550 $\pm 330 \mathrm{~mm}$ WEQ and $520 \pm 380 \mathrm{~mm}$ WEQ in the model and the field data, respectively. The model gives a sublimation of $79 \mathrm{~mm}$, compared to $410 \mathrm{~mm}$ precipitation during the model run.

\section{Discussion}

The applied field methods illustrate the snow distribution in the study areas and also the time evolution of the snow cover very well. The ground penetrating radar system allows one to cover large areas with little field effort, compared to manual measurements. The pulling snowmobile, as well as the radar sledge itself, densify the snow on the radar profiles. This problem is eliminated by calibrating the radar on the track directly between the antennas under the radar sledge. Interpolation of the field data by Kriging produces a snow distribution which could be expected in nature. The data coverage does not include steep slopes, introducing a larger interpolation error at these locations. Still, the data coverage is sufficient to include both accumulation and erosion areas in the plots. Small topographic features, such as melt water channels and moraines, cause sudden snow depth changes over short distances of only a few metres. In comparison to field data based on a small number of transects (Pomeroy et al., 1997; Gauer, 1998) or aerial photography (Liston and Sturm, 1998), the presented data is an improvement in resolution and accuracy, and presents a valuable tool for the validation of three-dimensional snowdrift models.

The results from the MEMO model show the model's nu- 


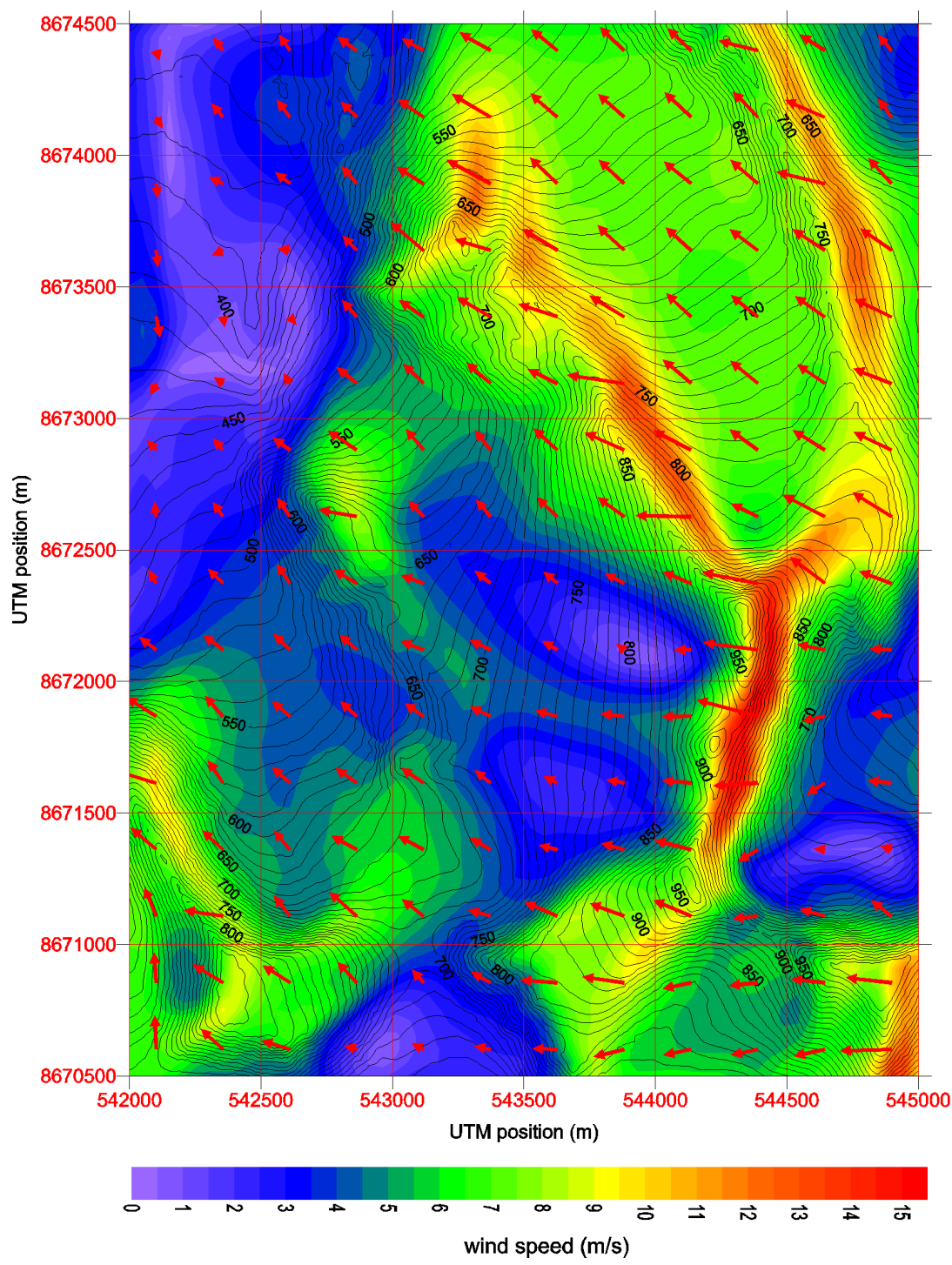

Fig. 6. Wind field in the Drønbreen area for uniform wind $(10 \mathrm{~m} / \mathrm{s})$ from east. The arrows show the wind direction. The wind speed is indicated by the shading and the size of the arrows.

merical capability of simulating wind fields in steep mountainous terrain at a high resolution. The strongly varying wind direction shows that statistical models that only change the wind speed in the terrain (Liston and Sturm, 1998; Pomeroy et al., 1997) are not applicable in complex terrain. However, the high computing capacities needed for such a model limit the number of cases which can be simulated. Five wind directions (N, NE, E, SE, S) at one wind speed $(10 \mathrm{~m} / \mathrm{s})$, as used in this study, should be considered as the minimum number of needed wind simulations for our case.

The results of the drift model are promising, considering the simplicity of the model and the limited number of available wind fields. The deviations of simulated and observed snow distribution may be caused by four major reasons:

1. The limited number of available wind fields. The applied approach uses the same wind field for all wind speeds over the threshold value, causing an underesti- mation of drift in very strong wind conditions. The lack of wind fields for different wind speeds causes the same erosion and accumulation areas for all wind speeds and prohibits the altering of erosion and accumulation patterns due to wind speed variations at a single grid point. Wind fields for five different wind speeds and eight wind directions should be used.

2. Equilibrium snowdrift profiles at all grid points. The assumption causes the drift transport to be higher behind bare ground areas than observed in nature. Takeuchi (1980) estimates the distance needed to achieve an equilibrium snowdrift profile to be $200-400 \mathrm{~m}$. The effect of the needed fetch was included in models by Pomeroy et al. (1997), Liston and Sturm (1998) and Essery et al. (1999) and has to be implemented in future versions of the model. 




Fig. 7. Simulated snow depth in the Drønbreen area at the end of the winter season (19 April 1999). For orientation the data coverage from the field survey is shown: strong black lines are radar profiles, black crosses indicate areas with bare ground. The pink areas are blank from the interpolation.

3. Constant threshold velocity throughout the winter. The response of the snow cover to the wind is strongly dependent on the threshold wind speed of the snow. Since the snow properties change with time, the threshold velocity should follow these changes.

4. Limited applicability of Pomeroy and Gray's saltation formulation. The applied saltation routine may introduce an error to the drift concentration calculated for each grid point (Lehning et al., 2000).

The results from the simulation show that the use of stationary wind fields is a promising approach. A complete classification of wind fields for different speeds and directions is the first priority to improve the results. Furthermore, the assumption of equilibrium profiles should be replaced by a routine that considers the effect of the needed fetch.

\section{Conclusion}

High resolution snow distribution measurements by ground penetrating radar in two study areas produced a valuable data set for the validation of snowdrift models. The erosion and accumulation pattern, as well as the time evolution of the snow cover, is included in the data set. The applied ground penetrating radar is a practical tool to achieve high resolution data coverage with a comparably low field effort.

A three-dimensional snowdrift model has been developed and was tested against the field data. The model is based on wind simulation from a mesoscale meteorological model, which is able to produce detailed wind fields in steep complex terrain. The comparison of the drift model results with the field data shows that the model produces promising snow distributions from the five applied wind fields. A complete classification of wind fields for different wind speeds and di- 
rections is needed to improve the results. The high resolution snowdrift data will help to verify the results of future snowdrift models.

Acknowledgements. Thanks to O. Brandt for the field assistance and the technical unit at UNIS for the support. The Norwegian Polar Institute gratefully provided the topographic data. The work was founded by the Norwegian Research Council, project number 122462/720 and 121740/410. Supercomputing resources were made available by the Norwegian Research Council.

\section{References}

Annan, A. P., Cosway, S. W., and Sigurdsson, T.: GPR for snowpack water content. Proceedings of the Fifth International Conference on Ground Penetrating Radar (Kitchener, Ontario, Canada): 465-476, 1995.

Bintanja, R.: The contribution of snowdrift sublimation to the surface mass balance of Antarctica, Annals of Glaciology, 27: 251259, 1998

Budd, W. F., Dingle, W. B. J., and Radok, U.: The Byrd snow drift project: outline and basic results, in Ruben, M. J., ed: Studies in Antarctic meteorology, Washington, D.C., AGU, (Antarctic research series, 9, 71-87, 1966.

Dery, S. J., Taylor, P. A., and Xiao, J.: The thermodynamic effects of sublimating, blowing snow in the atmospheric boundary layer, Boundary layer meteorology, 89, 251-283, 1998.

Essery, R., Long, L., and Pomeroy, M.: A distributed model of blowing snow over complex terrain, Hydrological processes, 13, 2423-2438, 1999.

Flassak, T.: Ein nicht-hydrostatisches Model zur Beschreibung der Dynamik der planetaren Grenzschicht, Ber. VIDZ, Reihe 15, VDI Verlag Düsseldorf, Germany, 1990.

Gauer, P.: Blowing and drifting snow in alpine terrain: numerical simulation and related field measurements, Proceedings of the international symposium on snow and avalanches, Chamonix, Annals of Glaciology, 26, 174-178, 1998.

Grønås, S. and Dagrun Sandvik, A.: Numerical Simulations of local winds over steep orography in the storm over north Norway on 12 October 1996, J. of Geophysical Research, 104, 1-12, 1999.

Hagen, J. O., Liestol, O., Roland, E., and Jörgensen, T.: Glacier Atlas of Svalbard and Jan Mayen, Norwegian Polar Institute, medeleser, No. 129, 145, 1993.

Johnson, G. D. B.: Nogle ord om snedreev, snefog och snefonner, P. T. Mallings forlags boghande, Christiania, Reprinted in faximilia Scientia et Tecnica Norvegica 31, NTH, Trondheim, 1969, 22, 1852.

Lehning, M., Doorschot, J., and Bartelt, P.: A snowdrift index based on SNOWPACK model calculations, Annals of Glaciology, 31,
5382-3865, 2000

Liston, G. E. and Sturm, M.: A snow-transport model for complex terrain, J. Glaciology, 44, 498-516, 1998.

Mann, G. W., Anderson, P. S., and Mobbs, S. D.: Profile measurements of blowing snow at Halley, Antarctica, J. of Geophysical Research, 24 491-24 585, 2000.

Mellor, M.: Blowing Snow. Cold regions science and engineering part iii, section A3c, Hanover, New Hampshire: 80, 1965.

Michaux, J. L., Naaim-Bouvet, F., Naaim, M.: Drifting snow studies over an mountainous instrumented site: Measurements and numerical model at small scale, Annals of Glaciology, 32, 2000.

Moussiopolous, N.: The Zooming model, model structure and application, EUROTRAC Int. Sci. Secr., Garmisch-Patenkirchen, Germany: 260, 1994.

Norem, H.: Utforming av veger i drivsnöområder (design of roads in drift snow areas), Norges Tekniske Hoögskole, Trondheim: 131, 1974.

Pomeroy, J. W. and Gray, D. M.: Saltation of snow, Water resources research, 26, 1583-1594, 1990.

Pomeroy, J. W., Marsh, P., and Gray, D. M.: Application of a distributed blowing snow model to the Arctic, Hydrological processes, 11, 1451-1464, 1997.

Sand, K. and Bruland, O.: Application of Georadar for snow cover surveying, Nordic Hydrology, 2, 4-5, 361-370, 1998.

Schmidt, R. A.: Sublimation of wind transported snow- a model, U. S. forest service research paper no. RM-90, Rocky Mountain forest range experiment station, U. S. department of agriculture, Fort Collins, May, 24, 1972.

Schmidt, R. A.: Threshold Wind-speeds and elastic impact in snow transport, J. Glaciology, 26: 453-467, 1980.

Sensors and software: pulseEKKO 1000 ground penetrating radar system, user's guide: Sensors and Software inc., Canada, 80, 1995.

Sundsb $\varnothing$, P. A. and Bang, B.: Calculation of snow drift around roadside safety barriers. Proceedings of the international snow science workshop 1998, Sunriver, Oregon, 279-283, 1998.

Tabler, R. D.: Geometry and density of drifts formed by snow fences, J. Glaciology, 26, 405-419, 1980.

Tabler, R. D.: Snow fence handbook, Tabler association, Laramie, Wyoming, 1988

Tabler, R. D.: Design guidelines for the control of blowing snow, National research council, Washington, 364, 1994.

Takeuchi, M.: Vertical Profile and horizontal increase of drift snow transport, J. Glaciology, 26, 481-492, 1980.

Thiis, T. K.: A comparison of simulations and full scale measurements of snowdrifts around buildings, Wind and structures, 3 , $1-10,1999$.

Zhonglong, W. and Yuan, C.: Research on prevention of snowdrifts by blower fences, J. Glaciology, 26, 435-445, 1980. 